University of Nebraska - Lincoln

DigitalCommons@University of Nebraska - Lincoln

Textile Society of America Symposium

Proceedings

Textile Society of America

$10-2020$

\title{
A Compared Study of Miao Embroidery and Ancient Chinese Embroidery: The Cultural and Historical Significances
}

Tomoko Torimaru

Follow this and additional works at: https://digitalcommons.unl.edu/tsaconf

Part of the Art and Materials Conservation Commons, Art Practice Commons, Fashion Design Commons, Fiber, Textile, and Weaving Arts Commons, Fine Arts Commons, and the Museum Studies Commons

This Article is brought to you for free and open access by the Textile Society of America at DigitalCommons@University of Nebraska - Lincoln. It has been accepted for inclusion in Textile Society of America Symposium Proceedings by an authorized administrator of DigitalCommons@University of Nebraska - Lincoln. 


\title{
A Compared Study of Miao Embroidery and Ancient Chinese Embroidery: The Cultural and Historical Significances
}

\author{
Tomoko Torimaru \\ tomochi69@hotmail.com
}

\section{Introduction}

With no written script, the Miao have relied on textile making as their method for recording their culture. Keeping textile traditions unchanged through the centuries ensured an enduring, unwavering, shared legacy throughout a history of diaspora. By examining Miao textiles and traditional practices, valuable insight can be gained into their background as a people whose migration is known to have been long and arduous yet whose origins remain unconfirmed.

Although today's Miao live primarily in southern China, historically they were believed to have once inhabited northern China near the Huanghe (Yellow River), later to move nearer the Changjiang (Yangzi River). ${ }^{1}$ Over two thousand years ago, they began migrating southwest. The majority of Miao now live in Guizhou with a population estimated at 4.3 million. Some members of Miao subgroups, most notably the Hmong people, continued migrating outside of China into southeast Asia and beyond.

One of my most interesting findings concerns the "ancient" chain stitch embroidery technique. Only the Miao have been observed practicing it in the present day. Not only has this research uncovered a unique technique, additional findings actually trace the Miao history to a specific northern area in ancient China at least as far back as the Warring States period (770-221 BC). Analysis of ancient embroidery samples suggests a common ground between the Miao and ancient Chinese civilizations.

These important discoveries are a result of numerous field studies I conducted in Guizhou Province, People's Republic of China. I base my work on authenticity, accuracy, and hands-on practice in situ.

\section{Miao Embroidery}

Throughout the course of my field research, I have studied over 50 types of stitches and fabric piecework prevalent in the Miao villages of Guizhou. ${ }^{2}$ While unusually skilled at noncounted or "free" embroidery, Miao are excellent at counted thread embroidery and working on cloth with the back side facing up. This impressive ability illustrates a deeply ingrained knowledge of and familiarity with textile's physicality, structure and pattern. Remarkably, the Miao embroider without a pre-marked design although they sometimes use a pattern stencil. They use a needle to scoop multiple stitches at one time, as with a running stitch, or by making one stitch at a time (Table 1).

Above all, the most interesting finding is the discovery of two distinctly different techniques of chain stitch that the Miao practice in their embroidery work. Certainly, this is important in terms of critical documentation for posterity. More significantly, however, when combining these findings with similarities in ancient Chinese textiles, the

\footnotetext{
${ }^{1}$ Masataka Suzuki and Yoshiko Kanamaru, A Minority Tribe of Southwest China-Ethnographic Survey of the Miao in Kweichou Province (Japan: Kokin Press, 1985), 17.

2 Tomoko Torimaru, One Needle, One Thread (USA: University of Hawaii Art Gallery, Department of Art and Art History, 2008), 7-69.
} 
historical implications suggest a shared cultural platform between Miao and ancient Chinese cultures.

\begin{tabular}{|l|l|}
\hline ("free") embroidery & Running stitch \\
& Stem stitch \\
Back stitch \\
French knot \\
Chain stitch \\
"Ancient" chain stitch \\
Open chain stitch \\
Double "ancient" chain stitch \\
Pulling stitch \\
Double pulling stitch \\
Couching stitch \\
Weaving stitch \\
& Double-twist knot stitch \\
Satin stitch with stencil \\
Straight stitch \\
\hline Counted thread & Satin stitch: backside up \\
embroidery & Darning stitch \\
Switchback darning stitch: backside up \\
Double-sided blackwork \\
Cross stitch \\
Cross stitch: backside up \\
Half cross stitch: backside up \\
Long-armed cross stitch \\
Triple long-armed cross stitch \\
Satin stitch, back side up, single sided \\
Oblique cross stitch \\
Double row cross stitch \\
Double row cross stitch, back side up \\
\hline
\end{tabular}

Table 1. Common Stitches in Miao Embroidery (Torimaru, 2008)

\subsection{Standard Chain Sew up}

One type of chain stitch used by the Miao is not unlike the standard Western style. This stitch is used to create strong linear designs. Skillful maneuvering of thread tension while making one link and closing another creates an evenly placed line of chains (Figure 1).
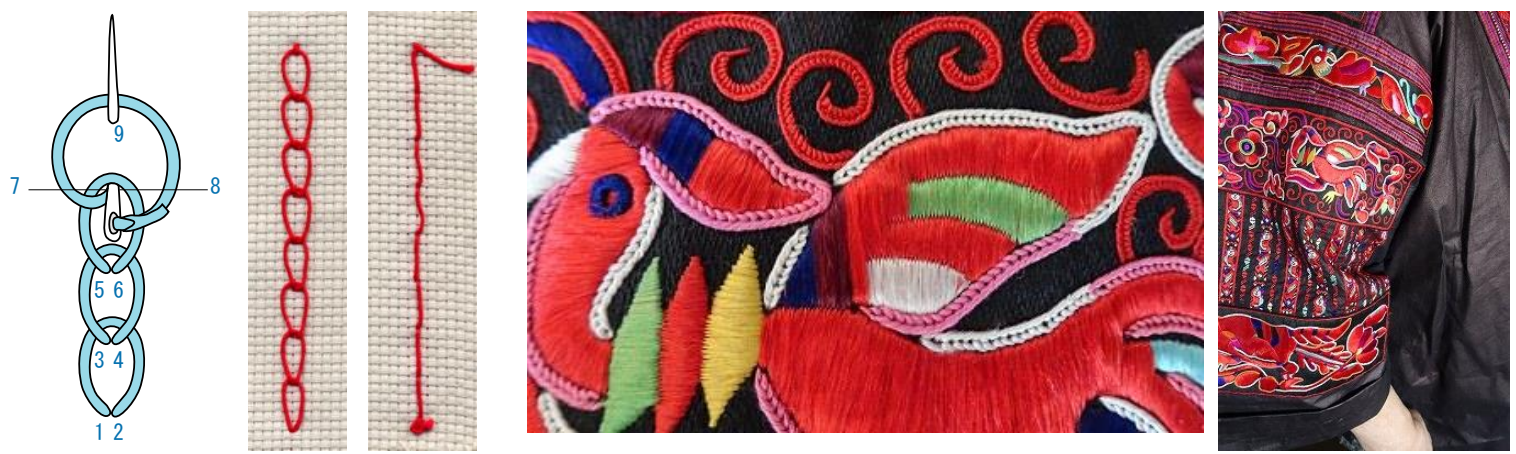

Figure 1. Standard chain stitch, detail. (from left to right) Diagram of stitch. The front side of the stitch. The back side of the stitch. An example in Shidong, Guizhou, China in 1990 (closeup and mid-range view).

(All images from author's collection) 


\section{2 "Ancient" Chain Stitch}

The second type - "ancient" chain stitch - is distinct from the "regular" or Western type of chain stitch both in appearance and execution. Notably, no other group except the Miao has been observed practicing this stitch nowadays. "Ancient" chain stitch is characterized by narrower chain loops and more fluid lines. Tension is more consistent and stitching action more articulate. The stitching execution (looping and advancing) is also backwards to that of the regular chain stitch (Figure 2). I have termed it "ancient" chain stitch for reasons that will be explained in the following section.
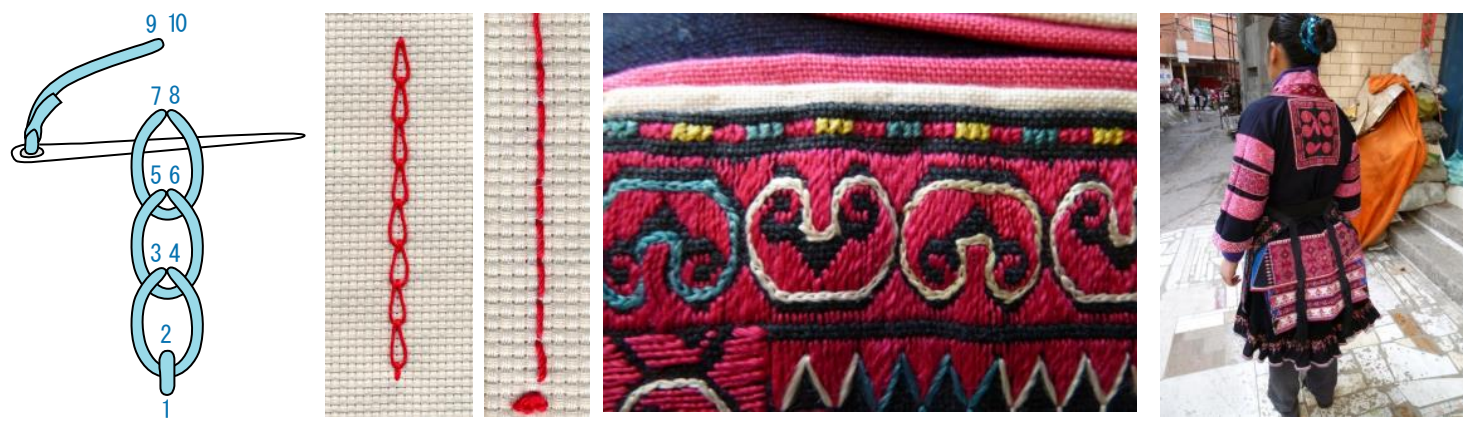

Figure 2. "Ancient" chain stitch, detail. (from left to right) Diagram of stitch. The front side of the stitch. The back side of the stitch. A detail and an overview in Wangjiashan, Guizhou, China in 2010. (All images from author's collection)

\section{Discovering Miao Techniques in Ancient Chinese Embroidery}

What is the history of "ancient" chain stitch? Where and when else was it in practice? Given that only the Miao are currently practicing this stitch, for insight I turned to older examples of embroidery.

Numerous textiles have been excavated from archeological sites in China, including the Jiangling Mashan No.1 Chu Tomb, Jingzhou, Hubei (Figure 3) and the Baoshan Chu Tomb, Jingmen, Hubei (Figure 4), Warring States period (770-221 BC), Xiejiaqiao No.1 Han Tomb, Jingzhou, Hubei (Figure 5) and the Mawangdui No.1 Tomb, Changsha, Hunan (Figure 6), Western Han period (206 BC-AD 8). These extant samples display flowing patterns often depicting fantastical animals using curving lines to suggest movement and energy. A mastery of skill is necessary to create such an articulate expression - from the fine continuous embroidery in the pattern details to the graceful movements of a motif. This type of fluidity could only be achieved using "ancient" chain stitch. 


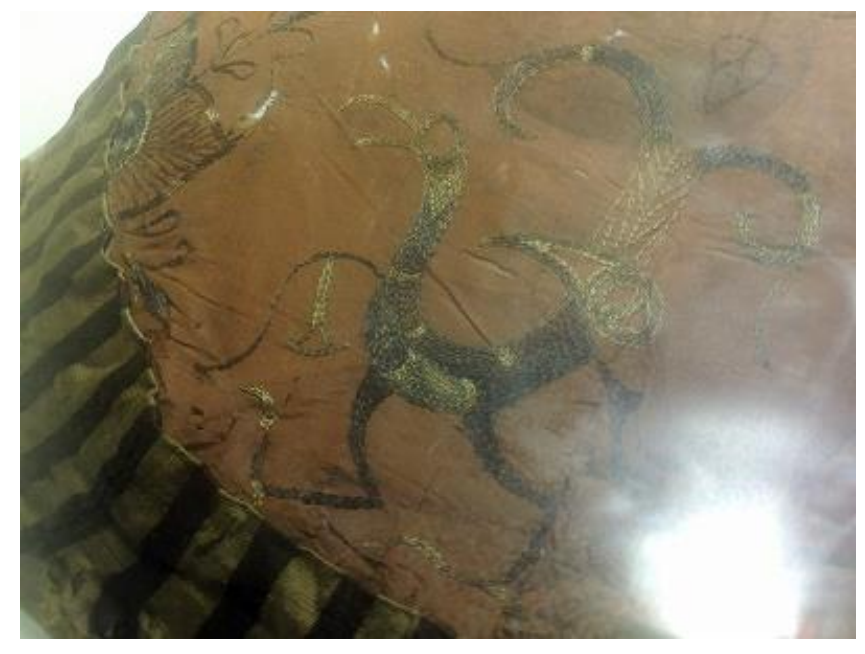

Figure 3. Red silk mirror bag embroidered with phoenix and floral patterns, Warring States Period. Unearthed from Jiangling Mashan No.1 Chu Tomb (475-221 BC), Jingzhou, China.

(This photo was taken by the author at Jingzhou Museum, Hubei, China in 2015.)

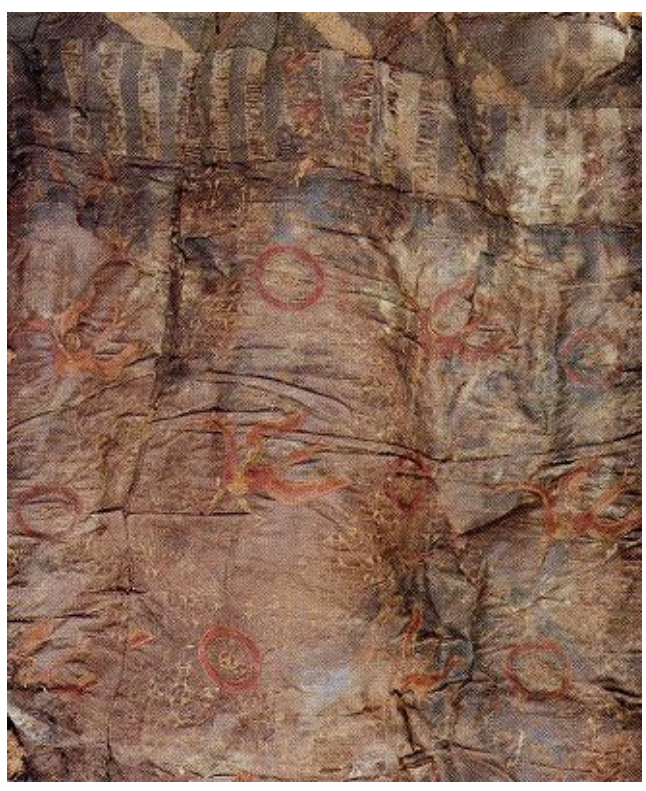

Figure 4. Embroidered with phoenix patterns, Warring States Period. Unearthed from Baoshan No.2 Chu Tomb (About 4th century BC), Jingmen, China.

(Hubeisheng, 1991, 10)

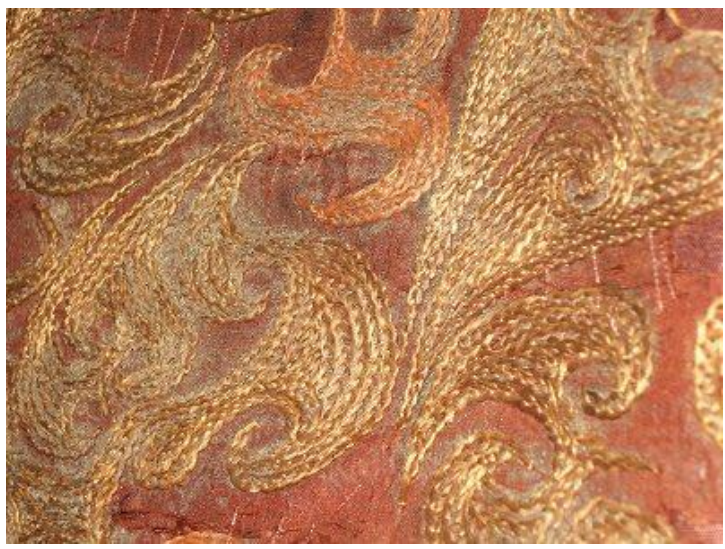

Figure 5. Embroidery on the cover of a coffin, Western Han Period. Unearthed from Xiejiaqiao No.1 Han Tomb (206 BC-AD 24), Jingzhou, China. (This photo was taken by the author at Western Han Nan Yue Wang Museum, Guangzhou, China in 2009.)

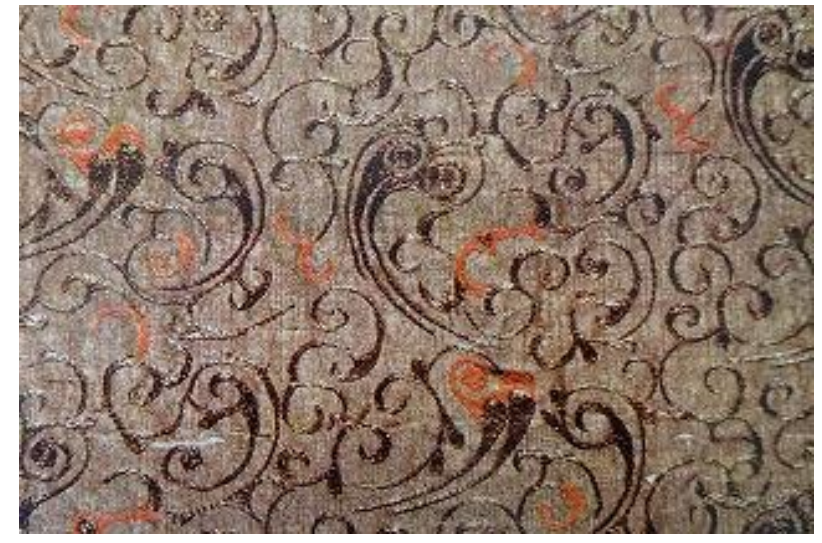

Figure 6. Embroidered textile, Western Han Period. Unearthed from Mawangdui No.1 Han Tomb (About 2nd century BC), Changsha, China. (Hunansheng, 1973 (Volume 2), 123)

A broad examination of historical Chinese embroideries shows that satin stitch, couching stitch, and decorative knotted stitch emerged as the prevailing types after the Tang period (AD 618-907). By that time, use of the "ancient" chain stitch had almost disappeared. The regular chain stitch, when present, was primarily used for linear elements. Today, all of the four dominant artistic styles of Chinese embroidery $-\mathrm{Su}$ embroidery (Suzhou, Jiangsu), Xiang embroidery (Hunan), Shu embroidery (Sichuan), and Guang embroidery (Guangdong) - exclusively use satin stitch. 
If "ancient" chain stitch appeared in ancient Chinese embroideries, could there be a traceable connection between the Miao and ancient Chinese cultures? Why did the stitch disappear from Chinese embroidery? To gain a larger view of its usage in history, I focused the research on three points: ancient embroidery patterns, chain stitch techniques in ancient times, and dates and locations of excavated artifacts.

\subsection{Ancient Decorative Patterns}

Decorative patterns were present throughout everyday aspects of ancient Chinese life: lacquer ware, bronze ware, ceramics, instruments, and, of course, textiles. Designs reflected the country's prevailing cultural beliefs at the time. During the Yin period (1700-1046 BC), Western Zhou period (1100-771 BC), Warring States period (770-221 BC) and Qin period (221-206 BC), a variety of patterns like arabesques and mountains made an appearance but the predominant design was animal pattern, which was based on mythical, mystical creatures such as the dragon, phoenix and tiger etc (Figures 7 and 8). Decorative art from the Western \& Eastern Han period (206 BC-AD 220) and Six Dynasties Period (222-589 AD) reflects a strong belief in 気 Qi. Viewed as the vital force of life or 'energy flow,' "Qi" can be described as the ethereal substance of which everything is composed of. This 'energy flow' was represented in design as a stylized pattern of swirling, fluid, unbroken lines to depict dragons, phoenixes, and other mystical creatures (Figures 9 and 10).

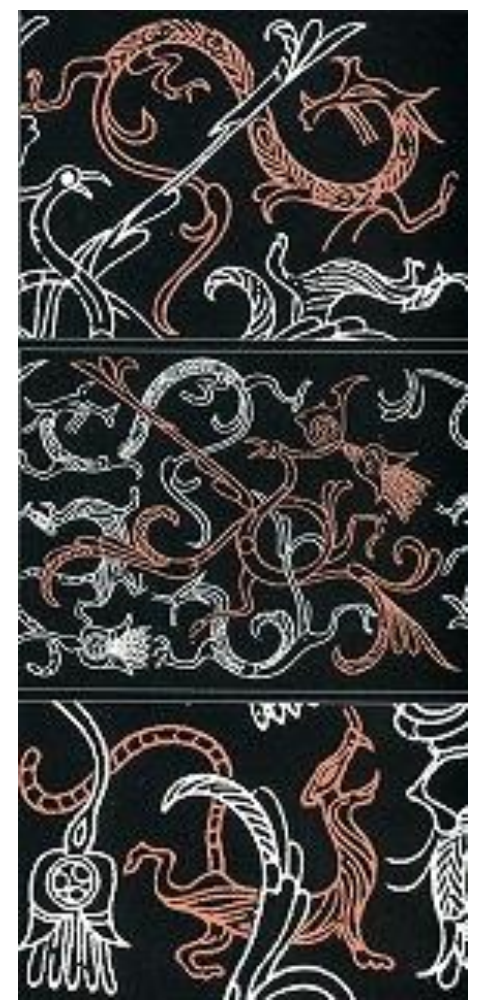

Figure 7. Design patterns (the dragon, phoenix and tiger) of an embroidered textile from Jiangling Mashan No.1 Chu Tomb (475-221 BC), Jingzhou, China. (NHK, 2000, 94)

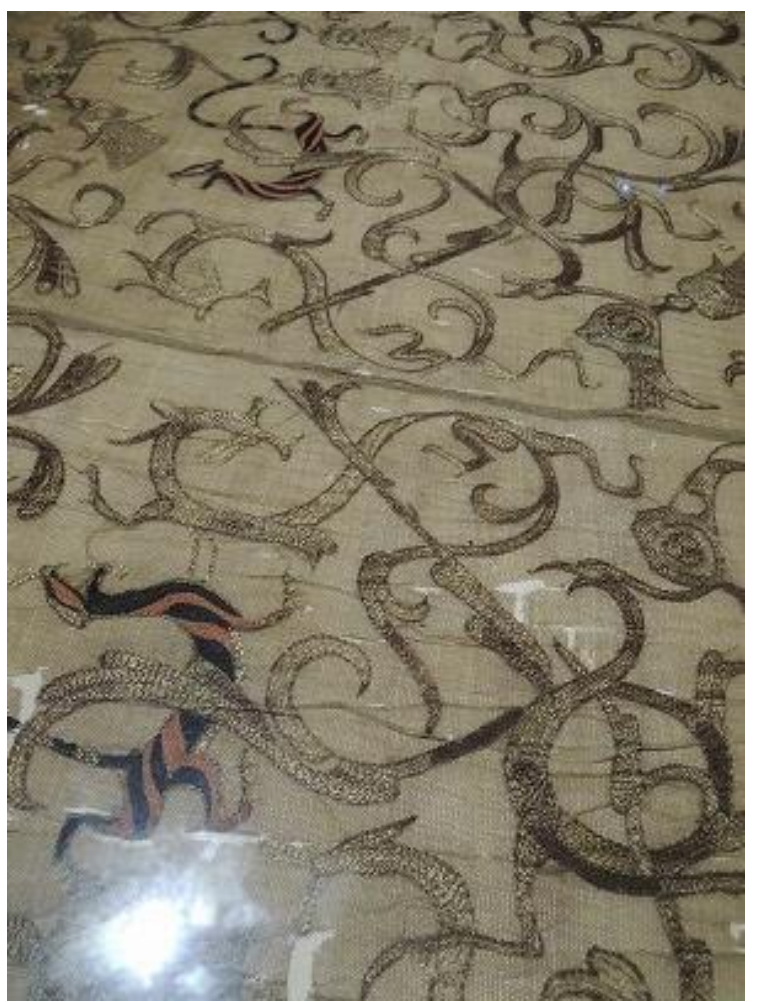

Figure 8. Embroidered with the dragon, phoenix and tiger patterns. Unearthed from Jiangling Mashan No.1 Chu Tomb (475-221 BC), Jingzhou, China.

(This photo was taken by the author at Jingzhou Museum in 2015 . 


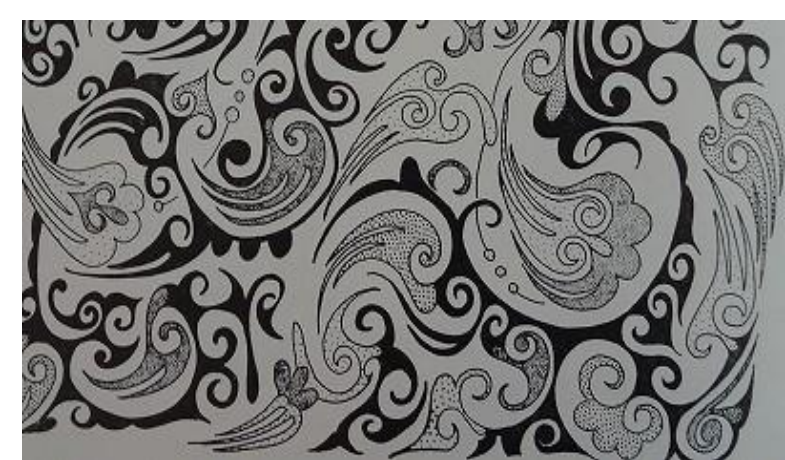

Figure 9. Design patterns of an embroidered textile from Mawangdui No.1 Han Tomb

(About 2nd century BC), Changsha, China.

(Hunansheng, 1973, Volume 1, 60)

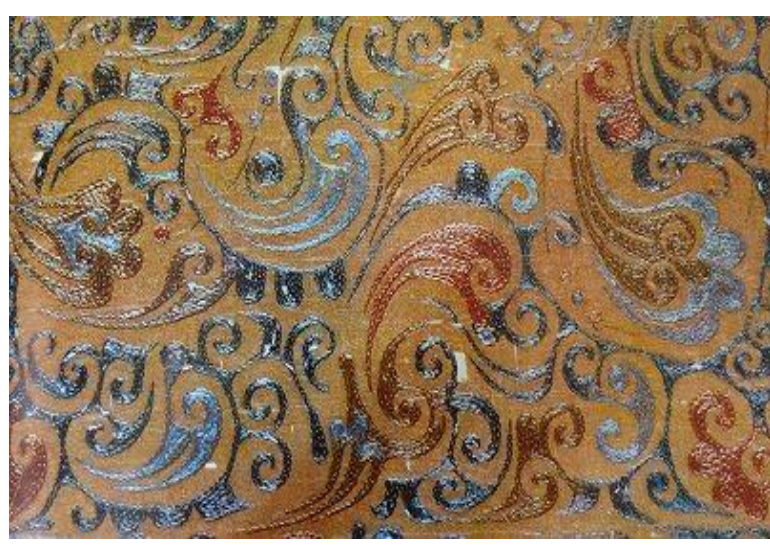

Figure 10. Embroidered textile, from Mawangdui No.1 Han Tomb (About 2nd century BC), Changsha, China.

(Hunansheng, 1973, Volume 2, 117)

Traces of "ancient" chain stitch can be found in the oldest embroidery artifact ever uncovered: a silk cloth that had been stuck to a lump of soil excavated at "Rujiazhuang" tomb, Baoji-city, Shangxi (Figure 11), dating back to the Western Zhou period (1100-771 BC). The area of Baoji-city was located in the west-central China, about $180 \mathrm{~km}$ west of Xi'an, where many small states inhabited by different racial groups were found. The Weihe (Wei River), the largest tributary of the Huanghe (Yellow River), flows alongside of Baoji-city. Interestingly, the Miao indicated that, according to oral history, this was the location of their original habitat.

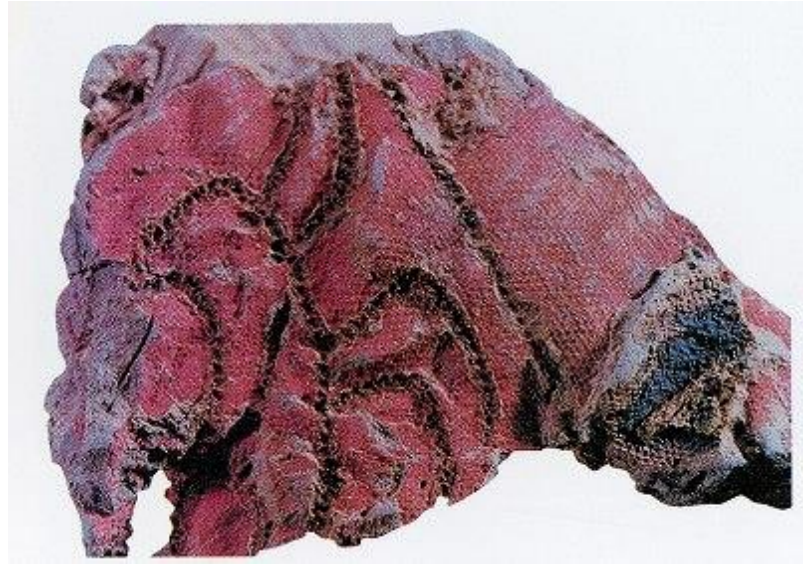

Figure 11. A silk cloth that had been stuck to a lump of soil from Rujiazhuang tomb, Western Zhou period (1100-771 BC), Baoji, China.

(Huang, 1999, 39)

\subsection{Usage of the Chain Stitch Technique in Ancient Times}

Given the gracefulness of the swirling "Qi" style animal designs, chain stitch should be the most suitable embroidery stitch to employ. Specifically, it should not be the standard chain stitch but the "ancient" chain stitch, owing to its superior capability for finely detailed articulation and smooth curving lines. Additionally, it seems fitting that the chain stitch was used for this style: circular loops mirroring "Qi" movement and flow. 
In August of 2015, I visited the Jingzhou Museum in Hubei, China, where I saw some displays of articles from the Warring States period excavated from Jiangling Mashan No.1 Chu Tomb (Hubei, Jingzhou). Seeing the embroideries in person substantiated my suspicion: I am certain they were done using what I have termed the "ancient" chain stitch.

A reproduction is also on display at the museum. I haven't asked the museum curators which chain stitch was used for this reproduction, however, in some places on the chain stitch, I found one side of the loops being pulled, this suggests that they used the standard chain stitch (Figure 12). The original had a narrow chain loop, a highly fluid line and consistent tension. The reproduction should have been stitched using the "ancient" chain stitch (Figure 13).

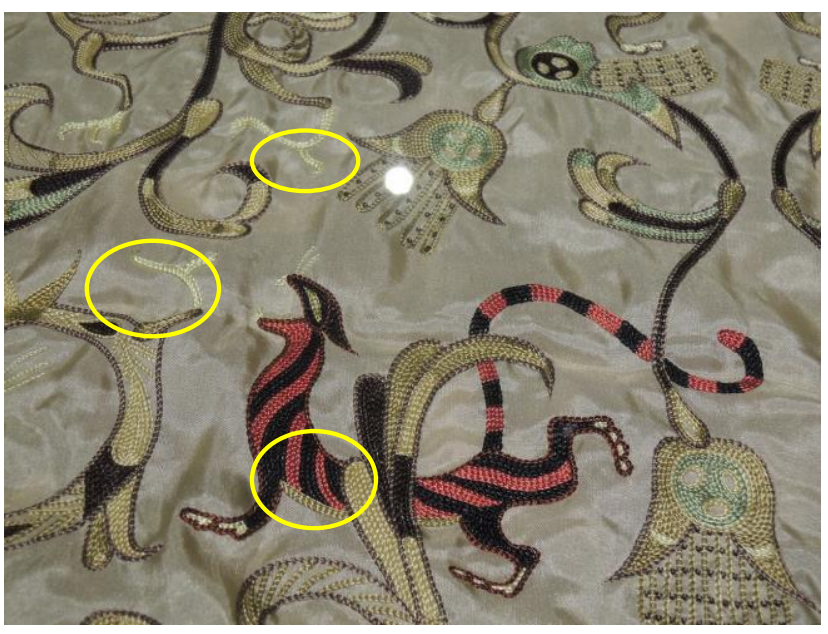

Figure 12. Reproduction; Embroidered with the dragon, phoenix and tiger patterns. The yellow circle marks indicate where one side of the loops being pulled.

(This photo was taken by the author at Jingzhou museum in 2015.)

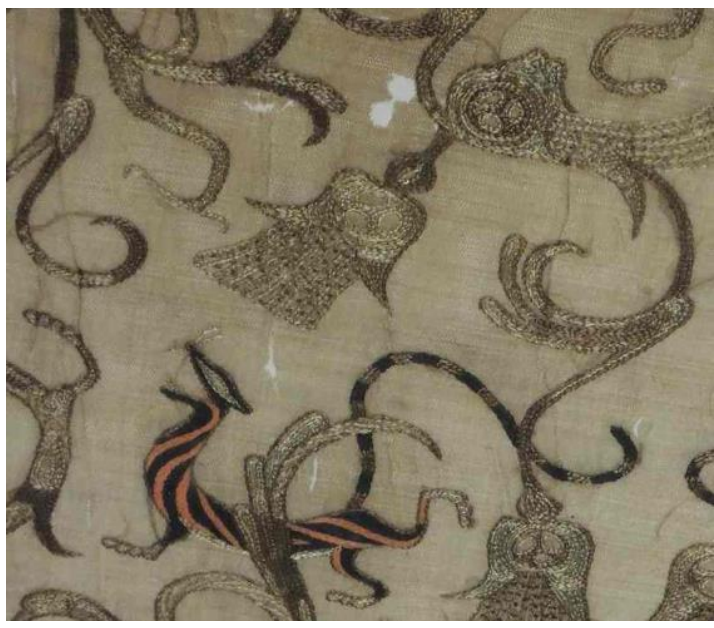

Figure 13. Original textile; Embroidered with the dragon, phoenix and tiger patterns. Unearthed from Jiangling Mashan No.1 Chu Tomb (475-221BC.), Jingzhou, China. (This photo was taken by the author at Jingzhou museum in 2015.)

\subsection{Identifying the Dates and Locations of Embroidery Artifacts}

Tracing the excavated artifacts to a specific time and location is critical to piecing together the evolution of the "ancient" chain stitch. Archaeological sites such as the Mashan No.1 Chu Tomb and the Baoshan Chu Tomb in Hubei, Jinzhou date back to the Warring States period in the Chu State area. Likewise, the Mawangdui No.1 Tomb in Hunan, Changsha, and Xiejiaqiao No.1 Tomb in Hubei, Jingzhou date back to the Western Han period and also belonged to the Chu State area.

Located in the north, the Chu State was presided over by no one particular racial group and no particular country. Instead, the area consisted of many small states conquering one another; this resulted in a changing political landscape and with it changing religious beliefs. Hence, a more universal, mystical philosophy like "Qi" was well suited to this time and place. 
Full examination of the tombs' excavated lots concluded that they were attributable to a cultural group different from the Han. My scholarly opinion holds that the exhumed items are connected to the Miao. How predominant their people were in this area is debatable. But the important point is that these findings corroborate the claim that the Miao inhabited the Chu State area as far back as the Warring States period and likely the Western Zhou period from which the oldest embroidery is traced. Furthermore, the Miao people almost certainly played an important role in the evolution of "ancient" chain stitch (Figure 14).
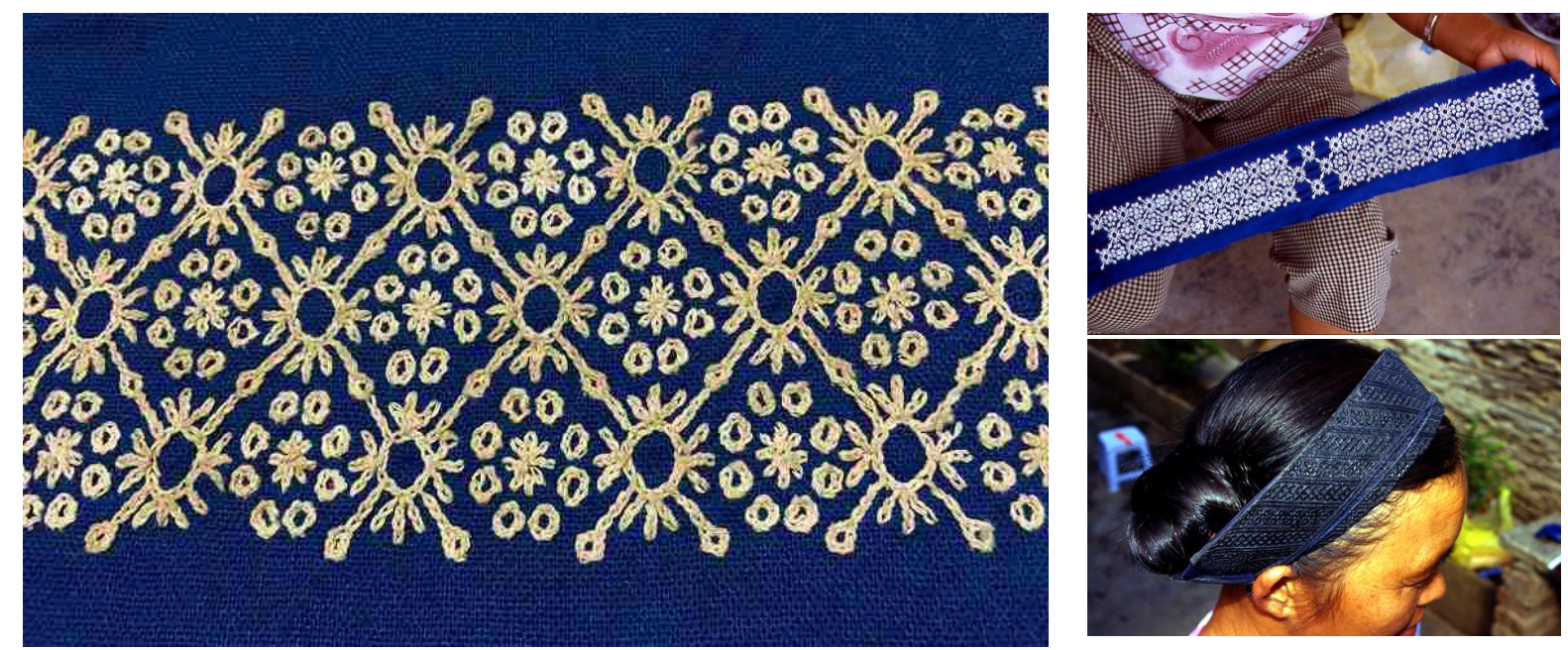

Figure 14. "Ancient" chain stitch for the headband (left). Completion of the embroidery using the "Ancient" Chain stitch (upper right). A Miao lady wearing a headband (lower right).

(These photos were taken by the author in Huaxi, Guizhou, China in 2006.)

\subsection{Shift of Techniques in Chinese Embroidery}

When the Sui (AD 581-618) and Tang (AD 618-907) periods came, a new style of symbolic motifs grew in popularity, such as the elegant "peony Tang grass pattern," blossoms and lions. These motifs seemed more "grounded" than the previously favored "Qi" style with its mythical creatures and swirling patterns. Even dragons were depicted as more earthbound than otherworldly. Hence, embroidery stitches changed to suit the new forms of expression. "Ancient" chain stitch disappeared from the mainstream giving over to satin stitch, couching stitch, and decorative knotted stitch.

\section{Conclusion}

At the present time, Miao is just one of 56 minority groups in China. However, the results of my research on Miao embroidery - in particular my findings on "ancient" chain stitch and its identifiable appearance in dated relics from ancient Chinese culture - is strong evidence of a close historical connection between the Miao and ancient civilizations in China. The Miao certainly influenced ancient Chinese embroidery and had a significant presence in the Chu State during the Warring States period (770-221 BC). Despite having no written language to document their history, relying only on oral tradition and textiles, the Miao can now substantiate their place in history. 


\section{Bibliography}

Gao, Hanyu and Hengxian Tu. Yizhuang. Shanghai: Shanghai Guji Press, 1996.

Guizhousheng Bianjizu. Miaozu Shehui Lishi Diaocha. Guiyang: Guizhou People's Press, 1986.

Han, Sheng. Famen Temple Cultural Relics. Beijing: Wenwu Press, 2009.

Huang, Nengfu and Juanjuan Chen. Zhonghua Lidai Fushi Yishu. Beijing: China Travel Press, 1999.

Hubeisheng Jingsha Tielu Kaogudui. Baoshan Chu-mu (Volume 2). Beijing: Wenwu Press, 1991.

Hunansheng Museum and Institute of Archaeology, Chinese Academy of Social Sciences. Changsha Mawangdui yihao Hanmu (Volume 1 and 2). Beijing: Wenwu Press, 1973.

Jiang, Yuqiu. "A practical study of Han Dynasty costumes taking the physical objects unearthed from the Han Tomb No.1 at Mawangdui, Chang sha." Beijing: ART \& DESIGN RESEARCH, Vol. 3, 2012.

Nippon Hoso Kyokai (Japan Broadcasting Corporation) (NHK). The Chinese Exhibition. Japan: NHK, 2000.

Suzuki, Masataka and Yoshiko Kanamaru. A Minority Tribe of Southwest China-Ethnographic Survey of the Miao in Kweichou Province. Japan: Kokin Press, 1985.

Torimaru, Sadae. Spiritual Fabric. Japan: Nishinippon Newspaper Co., 2006.

Torimaru, Sadae and Tomoko Torimaru. Imprints on Cloth. Japan: Nishinippon Newspaper Co., 2004.

Torimaru, Tomoko. One Needle, One Thread. USA: University of Hawaii Art Gallery, Department of Art and Art History, 2008.

Wang, Yarong. Chinese Folk Embroidery. UK: Thames and Hudson, 1987. 